\title{
APRENDIZAGENS COOPERATIVAS NA CONSTRUÇÃO DE PORTFÓLIOS VIRTUAIS: UMA EXPERIÊNCIA NA INICIAÇẨO À DOCÊNCIA
}

\author{
Martha Marlene Wankler Hoppe, UERGS, marta.hoppe@gmail.com \\ Silvana Corbellini, UFRGS, silvanacorbellini@gmail.com
}

\begin{abstract}
RESUMO
A interação em ambientes virtuais e o compartilhamento de experiências e conhecimento na iniciação à docência são aprendizagens necessárias à formação inicial de professores. Este estudo objetivou a análise das aprendizagens cooperativas na elaboração de portfólios virtuais com o uso da ferramenta PBWorks, no programa de iniciação à docência - Pibid Uergs. O referencial teórico abordou o processo de aprendizagem como construção de conhecimento, na referência de Piaget, e na transposição de práticas pedagógicas vivenciadas presencialmente nas escolas para o ambiente de interações virtuais. A metodologia utilizada foi de estudo de caso único com análise de tipo descritivo. Os instrumentos de coleta de dados utilizados foram entrevistas, questionários online e análise documental. Os resultados obtidos revelaram que entre as dificuldades enfrentadas estão a transposição de experiências vivenciadas em práticas pedagógicas com o registro e avaliação destas práticas. A seleção das informações postadas $e$ as questões éticas são temas de preocupação dos estudantes. A aprendizagem cooperativa acontece como resultado das interações entre os licenciandos e com os coordenadores, nas trocas virtuais e presenciais.
\end{abstract}

Palavras-chave: Aprendizagem Cooperativa. Portfólio Virtual. Docência.

\section{ABSTRACT}

The interaction in virtual environmental the sharing of experiences and knowledge in the initiation to teaching are the learning for initiating a teaching career. This study aimed to analyze the cooperative learning in the preparation of virtual portfolios using the PBWorks tool in the Pibid program. The theoretical approach used learning process as knowledge in construction using the Piaget's concepts. It also analyzes the transposition of pedagogic practices experienced in school in the virtual environment records. The methodology was a single case study with descriptive analysis. The data collection instruments were interviews, online questionnaires and document analysis. The results showed that between the difficulties faced are the transposition of practices experiences in face to face teaching and its record and evaluation. The selection of information posted in the virtual portfolios and its ethical issues are students concerns. Cooperative learning happens as a result of interactions between undergraduate students and their coordinators, during the virtual and face-to-face meeting.

Keywords: cooperative learning. virtual portfolio. initiation to teaching

\section{INTRODUÇÃO}

A construção de portfólios virtuais e o uso da plataforma PBWorks no ensino são temas tratados em estudos recentes sobre processos de ensino e aprendizagem. $\mathrm{Na}$ educação a distância e como ferramenta complementar na educação semipresencial, o uso do PBWorks é reconhecido como um espaço efetivo de compartilhamento e construção de conhecimento (Real, Corbellini e Santos, 2012). Em relação ao uso da plataforma PBWorks, os estudos de Bona e Basso $(2009,2010)$ oferecem relatos significativos sobre a construção de portfólios virtuais no ensino da matemática. Os processos de aprendizagem analisados evidenciam a importância do trabalho de compartilhamento das percepções e raciocínios de cada aluno. Quando utilizados em cooperação e de modo contínuo, os portfólios virtuais possibilitam a abertura de perspectivas para novas formalizações.

O objeto deste estudo é parte do processo de construção do Programa de Iniciação à Docência da Uergs - Pibid Uergs que integra subprojetos nas áreas de Pedagogia, Artes Visuais, Dança, Música e Teatro. Com o edital de 2013 o programa cresceu e passou a integrar dez subprojetos, em sete cidades do interior do estado. Diante da necessidade de aproximar os licenciandos, coordenadores e supervisores e suas experiências nas diferentes unidades universitárias e aumentar a cooperação para o aprimoramento das ações desenvolvidas, foram implantados os portfólios virtuais em um site do projeto institucional. Nos portfólios são registrados os relatos individuais, ensaios, projetos e outros textos decorrentes das experiências de iniciação à docência. 


\section{OBJETIVO}

O objetivo deste estudo é de analisar a aprendizagem cooperativa resultante do processo de construção de portfólios virtuais na formação inicial de docentes. Para o desenvolvimento do estudo são apresentadas as concepções epistemológicas sobre a construção do conhecimento, o aprendizado e uso de ambientes virtuais de aprendizagem, e o portfólio na formação inicial de docentes.

\section{APRENDIZAGEM E COOPERAÇÃO EM AMBIENTES VIRTUAIS}

Este estudo parte do modelo pedagógico relacional, de acordo com a teoria de Piaget, que irá direcionar os princípios pedagógicos de implantação de portfólios virtuais no Pibid-Uergs. Neste modelo, o saber que o aluno adquiriu ao longo da vida servirá de base e de abertura para que ele continue a construir novos conhecimentos. A aprendizagem, segundo este modelo, é uma questão de descoberta, que acontece mediante um processo de construção.

No processo de aprendizagem por construções sucessivas o sujeito assimila os elementos daquilo que deseja conhecer e, após, acomoda, sendo que estes dois movimentos são responsáveis pelo processo de equilibração. A teoria da equilibração de Piaget envolve a tomada de consciência que consiste numa espécie de esclarecimento que faz com que o sujeito modifique um esquema de ação e o transforme num conceito: a tomada de consciência consiste, essencialmente, em uma conceituação (Piaget, 1977).

Entre os conceitos mais significativos de Piaget está o de abstração reflexionante. Este construto envolve dois processos: o reflexionamento e a reflexão. No reflexionamento, ocorre uma espécie de projeção sobre um patamar superior daquilo que foi tirado do patamar inferior (da ação à representação); e na reflexão, ocorre a reconstrução e reorganização sobre o patamar superior daquilo que foi assim transferido do inferior (Piaget, 1995). A abstração é categorizada pelas transformações no modo de apreensão do objeto do conhecimento que vão da ação à representação, em diferentes patamares de diferenciação. No processo de reflexionamento ocorre, inicialmente, o deslocamento dos observáveis, em função de sua conceituação progressiva e pela tomada de consciência que é a interiorização das ações. A reflexão consiste em refazer a organização prévia em função das novidades trazidas pelo reflexionamento (Becker, 2009). A compreensão e a análise dos aspectos envolvidos no aprendizado sobre a criação do portfólio e uso da ferramenta digital será fundamentada por esta perspectiva teórica.

A aprendizagem que ocorre nas interações mediadas em ambientes virtuais é associada ao modo de operar coletivamente e é associada aos termos colaboração e cooperação. Optamos pelo termo "aprendizagem cooperativa" para tratar da interação entre alunos e professores na plataforma PBWorks porque responde pela noção de trabalho conjunto: cooperar é operar em interação de modo a resultar em um trabalho coletivo. A aprendizagem cooperativa em situação escolar ou universitária não é dada ao sujeito que dela participa, é uma experiência de autonomia em constante construção e que impõe a descentração.

Corbellini e Corte Real (2012) abordaram o conceito de descentração no processo de aprendizagem cooperativa em ambiente virtual, ao analisarem a realização de trabalhos de conclusão em cursos a distância com a utilização da plataforma wiki (PBWorks). As pesquisadoras observaram o efeito das postagens dos alunos em relação a produção de questionamentos e conhecimentos gerados. Na pesquisa cooperativa esse efeito foi comparado ao resultado do "giro" do caleidoscópio: a cada giro uma nova imagem é formada. A aprendizagem em pesquisa cooperativa permite a promoção da autonomia, decorrente do processo de descentração, que ocorre nas trocas entre os sujeitos. 


\subsection{TRABALHANDO COM PORTFÓLIOS VIRTUAIS NA EDUCAÇÃO}

Nas primeiras referências sobre o uso de portfólios, segundo Rodrigues (2009), eles eram denominados de folder e estavam relacionados aos trabalhos dos alunos que eram guardados para serem, posteriormente, mostrados aos pais os quais podiam, inclusive, acrescentar comentários.

Este princípio que confere ao portfólio um meio de acompanhar a aprendizagem é mantido ainda hoje na educação. Compreende o conjunto de relatos, planejamentos, trabalhos e relatórios reunidos para mostrar o processo de produção de conhecimento do aluno ao longo de uma atividade ou curso. Em estudo sobre o uso de portfólios na educação, os autores concluiram que "As informações que o compõem podem e devem representar os esforços do indivíduo numa área de estudo determinada e demonstrar sua integração e aplicação no desenvolvimento dos trabalhos" (Alvarenga e Araújo, 2006, p. 138).

O portfólio, na formação inicial de docentes, é uma metodologia de promoção ou estímulo aos processos de reflexão sobre a prática pedagógica, revela o modo como o aluno percebe a aprendizagem vivenciada durante determinado período de tempo, possibilita o delineamento de uma estratégia para o conhecimento aprofundado do contexto de trabalho, forma a documentação e a avaliação do processo de aprendizagem do aluno e promove a interação entre os pares na construção coletiva de conhecimento. O portfólio tem uma função estruturante e organizadora, além de proporcionar espaço para a mostração (ostensão, ato ou efeito de mostrar) e revelação de potencialidades profissionais. As diferentes concepções sobre a aquisição do conhecimento irão incidir na supervisão dos alunos e na construção dos portfólios.

A ferramenta digital PBWorks foi escolhida para a construção do portfólio por constituir um espaço dinâmico e interativo que permite o compartilhamento das experiências de iniciação à docência e o exercício de textos coletivos.

A inclusão de experiências com o uso das tecnologias na interação em rede promove a qualificação da formação inicial na docência e deve incluir em sua proposta, a avaliação da relação entre o fazer e o pensar a aprendizagem como processo contínuo. O trabalho coletivo em rede e a construção de textos em ambiente virtual são experiências que devem compor o currículo dos professores em formação. A complexidade destas aprendizagens só poderá ser conhecida por meio da avaliação dos resultados e consistência dos registros. Importante destacar que a educação para o uso adequado da tecnologia é parte da educação para vida, deve incluir o debate sobre as questões éticas.

\section{METODOLOGIA}

A metodologia utilizada foi de estudo de caso único, qualitativo, de tipo descritivo. Esta metodologia permite explorar de modo contextual as situações decorrentes das intervenções na construção de portfólios virtuais ao longo do programa de iniciação à docência Pibid-Uergs. Foi utilizado o referencial teórico de Yin (2010), com análise descritiva de caso.

Participaram deste estudo, 50 bolsistas de iniciação à docência e 12 coordenadores de área do Pibid-Uergs. A coleta de dados foi realizada com a utilização de questionários enviados online, encontros presenciais para debate sobre a utilização da ferramenta PBWorks e do portfólio, além de entrevistas presenciais com estudantes do programa.

Foram enviados 230 questionários a todos os licenciandos do programa, sendo que 50 retornaram. Dos 17 questionários enviados aos coordenadores de área, 12 retornaram. Os questionários abordaram o conhecimento sobre a o uso do Portfólio como instrumento de aprendizagem, o uso da ferramenta do PBWorks como meio de registro das ações pedagógicas realizadas nas escolas e a aprendizagem na iniciação à 
docência. A análise dos Portfólios (disponíveis em www.pibiduergs.com) contribuiu para a compreensão sobre o modo como cada aluno refletia sobre a experiência.

Os procedimento para desenvolvimento do estudo incluíram duas reuniões com os coordenadores de área e um treinamento sobre a ferramenta PBWorks e seu uso como portfólio na iniciação à docência. A partir desse primeiro encontro foram agendados outros encontros para acompanhar as dificuldades sobre a construção dos portfólios e esclarecer dúvidas sobre o uso da ferramenta virtual com licenciandos e coordenadores.

Após cinco meses de utilização do portfólio virtual foi enviado aos licenciados e coordenadores do programa um questionário via e-mail e realizadas duas entrevistas presencias com estudantes do programa, selecionadas aleatoriamente. As questões éticas foram tratadas por meio de um consentimento livre e esclarecido, assinado pelos participantes que responderam ao questionário.

As unidades de análise foram selecionadas considerando a validade do estudo, que vem a ser, conforme Branquinho e Gomes (2006), os procedimentos de validade interna e externa. A validade interna é o significado dado ao processo de construção de um portfólio virtual, sua operacionalização, por meio do registro digitado, das ações na escola; e, como ocorreu a tomada de consciência com a transposição das experiências vivenciadas e cooperação dos envolvidos nessa construção. A validade externa corresponde às avaliações dos coordenadores e das postagens nos portfólios. Os coordenadores analisaram como acontece a aprendizagem na construção do portfólio virtual; como observam a disposição do bolsista para pensar de modo a transcender o pensamento operacional; como observam a disposição do bolsista para interagir com o ponto de vista do outro e construir a autonomia de pensamento.

A análise dos resultados foi feita de modo descritivo, segundo Yin (2010), e com a formulação teórica de construção do estudo de caso.

\section{APRESENTAÇÃO E ANÁLISE DOS RESULTADOS}

Os resultados são apresentados de modo a integrar os dados de entrevistas, os questionários e os portfólios.

O portfólio é definido pelos licenciandos como um espaço de armazenamento de trabalhos e como uma estratégia de avaliação contínua do processo de iniciação à docência no Pibid. A função do portfólio é associada aos termos: compartilhamento; visibilidade das atividades desenvolvidas; planejamento; reflexão das práticas; espaço de consulta; lugar de escrita (ou diário) das principais ideias, aflições, angústias e desafios enfrentados; autoavaliação; organização dos dados para pesquisa; meio de comunicação entre colegas bolsistas e coordenador de área.

Aluna do curso de Pedagogia

É uma estratégia que auxilia na avaliação contínua do processo educacional, nele é possível ter uma visão completa do que foi absorvido, com a explanação dos conteúdos. Nele é possível fazer uma retomada do que foi visto, permitindo uma melhor visualização e organização do que foi aprendido $e$ podendo acrescentar informações que acharmos necessárias para maior conhecimento.

A ideia do portfólio como um meio de avaliação e de autoavaliação também está associada à percepção de controle sobre a realização das tarefas do programa de iniciação à docência. Alguns alunos entendem os registros escritos com uma prova (de medir conhecimento) e controle sobre o desempenho. Nesta perspectiva, o portfólio também é visto como uma obrigação e mais uma tarefa a cumprir que não revela a riqueza dos encontros presenciais.

A relação entre a construção do conhecimento e o uso do portfólio virtual foi entendida pelos participantes de dois modos: de conformismo com um aprendizado como resposta às demandas do programa de iniciação à docência, e de crítica quanto ao 
valor dos portfólios virtuais e seus registros, considerando que estes não revelam a totalidade das vivências nas escolas.

Aluna de Artes Visuais

Para mim muito pouco, me parece que ficamos apenas na teoria, na obrigação da construção de textos, redações, para amostrar para alguém que avalia, mas o conhecimento dentro da escola, com professores, alunos, não percebo esse envolvimento humano ligado no portfólio, para mim serve apenas como uns registros. Não pretendo tratar assuntos diversos com meus alunos virtualmente, prefiro o contato humano, a troca de experiências direta com o colega, de que me adianta ler e não poder trocar essa experiência falando, ou chorando junto sei lá. Não gosto da frieza das redes sociais que aceita qualquer escrita, não importa se são verdadeiras ou não.

Aluna do curso de Artes Visuais

O Portfólio Virtual nos possibilita ter comunicação com os demais Pibidianos em horários além das reuniões e encontros. É um espaço onde podemos compartilhar inúmeros conhecimentos e registrar situações importantes e marcantes durante as semanas. Além disso, costumamos lançar artigos, vídeos e textos importantes para a construção do conhecimento em Arte e em educação em nossas páginas pessoais.

As respostas dos licenciandos revelaram que pensam o portfólio virtual como referência de aprendizagem, por meio de registros marcantes e de trocas de informações entre usuários. Também apresentaram a ideia do distanciamento entre o que é vivenciado e o que é registrado no portfólio. Constatamos que o compartilhamento ou troca de informações é citado pela maioria dos licenciandos como meio de aquisição de conhecimento. Questionamos sobre o tipo de conhecimento proporcionado nestas trocas: se correspondem a informações temporárias ou participam no processo de tomada de consciência sobre os conceitos internalizados. Na aprendizagem cooperativa, os conhecimentos são internalizados e transformados em novos conceitos, resultantes de um trabalho conjunto de aprendizagem.

Conforme análise de Cruz (2008), o excesso de informações que a internet possibilita aos usuários gera a ideia de que a informação por si só implica em conhecimento. $\mathrm{O}$ autor destaca a não-hierarquização, a descentralização e desterritorialização do saber e da informação como as principais características da sociedade da informação. Neste contexto, a construção do saber é comparada com uma prática de bricolagem em que a reunião de informações não admite a condução por uma lógica científica e caminha para uma conclusão inesperada. Também é associada a um contexto rizomático, em que qualquer ponto pode ser conectado a outro conforme conceito de multiplicidade e onde o processo de aprendizagem acontece graças à construção de link com diversas fontes de informação de saber e de aprender.

A existência de um processo aleatório na construção do conhecimento com a troca de informação entre os pares não é contraditório com a presença de um processo de escrita em cooperação. O tema da escrita - no caso do uso de portfólio virtual tratamos da digitação - revela a preocupação com o conteúdo das postagens e com o receio de reações desfavoráveis.

Aluna do curso de Teatro

Até agora, só registrei imagens que fiz. Tenho o primeiro relatório pronto para postar, mas como ele é "forte" e por medo meu das reações das supervisoras ao ler, não postei.

A preocupação quanto à publicidade de experiências subjetivas surge como resistência à postagem. Os estudantes estão acostumados com o uso de redes sociais como o Facebook que facilitam a circulação de ideias aleatórias e de modo transitório. No PBWorks cada aluno posta seus relatos com conteúdos resgatados da própria experiência de iniciação à docência, que permanecerão e receberão comentários dos colegas e coordenadores. Constatamos que a construção do portfólio é um processo 
desafiador tanto para licenciandos quanto para coordenadores, pois é uma atividade que exige a adoção de posições éticas e teóricas, e de contínuo movimento de reflexionamento e reflexão. Estas ações demandam o tempo para a assimilação e a elaboração de ideias na referência ao outro.

O empenho dos licenciandos em seguir investindo na tarefa é constatado pelas revisões constantes que eles realizam em seus portfólios. A constância no uso da ferramenta virtual e a permanência das informações online podem ser apontadas como fatores fundamentais para a promoção do reflexionamento sobre o registro das ações e da tomada de consciência na aprendizagem da docência, criando as condições para as transformações.

Coordenadores e licenciandos tinham, ao início da tarefa de construção dos portfólios, precário conhecimento sobre o uso de tecnologias digitais e ausência de conhecimento sobre o PBWorks. A superação do conflito exigiu e ainda exige o investimento constante de todos, coordenadores e alunos. Esta problemática foi assumida, inicialmente, como um compromisso do programa Pibid e, atualmente, vem oportunizando descobertas sobre o PBWorks, com atitude contínua de solidariedade e cooperação.

As dificuldades se mesclam às resistências quando o aluno se recusa a aprender como utilizar a ferramenta digital alegando suas fragilidades e mantendo o desconhecimento sobre seu uso. Entre os desafios citados pelos alunos estão a necessidade de compreensão da ferramenta e a postagem semanal. Alguns permanecem com seus registros em papel, escritos ou digitados em arquivo de texto. Em relação à publicidade do material, os alunos revelam tanto o cuidado e a preocupação quanto a sua qualidade e relevância.

A comparação entre a aprendizagem presencial e a realizada com o meio digital ainda está em debate. Mesmo que as reuniões dos licenciandos com o coordenador de área na universidade sejam citadas como mais produtivas que as interações no ambiente virtual, é possível observar o debate sobre as diferenças entre os processos de conhecimento gerados em encontros presenciais e aqueles que ocorrem com a construção de textos nos portfólios virtuais.

A aprendizagem cooperativa que acontece na convivência em espaços coletivos é potencializada pelas contribuições de cada participante, motivo pelo qual estas devem primar pela consistência e fecundidade. Contribuir de modo construtivo exige a descentração e a tomada de consciência de uma nova perspectiva de pensamento.

$\mathrm{O}$ processo de reflexionamento inicia no momento em que o texto é escrito e principalmente quando é lido e pensado após sua escrituração, pelo próprio aluno. Entretanto, a reflexão nem sempre acontece e o texto pode permanecer como um apanhado de impressões e percepções.

Considerando que a tomada de consciência é uma conceituação e que ela pode acontecer mediante inadaptações e conflitos (Piaget, 1977), podemos afirmar que o processo de construção dos portfólios virtuais promove a tomada de consciência sobre o que é a iniciação à docência. Os momentos de registro correspondem a organizações de ideias e pensamentos que podem levar a conceituações sobre o tema, dependendo do modo como esta experiência é tratada pelo licenciando nas reuniões, com seus pares e com os coordenadores de área.

$\mathrm{Na}$ análise dos portfólios de cada subprojeto foi constatado o tipo de registro e seus conteúdos: poemas e textos de pensadores da educação (imagem com uma frase ou poema); anotações curtas sobre o que ocorreu em cada dia na escola (um parágrafo com algumas frases); registros detalhados em período de tempo curto (um ou dois meses); relatos elaborados de algumas experiências (descrições mais elaboradas de intervenções pontuais); relatos detalhados e bem elaborados com ilustrações sobre uma sequência de observações; relatos de ações realizadas na escola com fotos; projetos de intervenções 
pedagógicas com fundamentação teórica; planos de aula sem fundamentação teórica; artigos elaborados em parceira e com fundamentação teórica (em apenas um dos subprojetos) e até ausência de registros.

Os registros acima categorizados compreendem percepções e pensamentos sobre as observações feitas nas escolas: anotações de ideias, narrativas de situações vividas e escritas espontâneas. Estas postagens não revelam a gama de experiências e aprendizagens que o programam de iniciação à docência proporciona. Para que a transposição didática aconteça de modo sistemático é necessária criar condições para a tomada de consciência sobre o que representa o portfólio nesse processo. Entendemos o caminho está traçado e em construção tanto para os estudantes que assumiram a tarefa com disposição para a aprendizagem quanto para aqueles que aceitaram apenas como compromisso junto ao programa. A reflexão como conceito, processo de pensamento e questionamento sobre as observações das práticas pedagógicas está registrada na resposta da aluna de Pedagogia:

Aluna do curso de Pedagogia

A reflexão é imprescindivel para o desenvolvimento do trabalho do professor. O profissional reflete sobre suas observações durante o planejamento, durante a prática, após a prática e finalmente faz uma reflexão sobre a reflexão, aperfeiçoando as suas práticas a cada ciclo, confirmando as suas concepções ou reformulando o que não deu certo, crescendo como profissional e como pessoa humana.

Nesse momento da construção dos portfólios observamos que os alunos estão em fase de ordenamento de suas percepções, ainda não organizados de modo a constituir os observáveis que garantem o reflexionamento e a reflexão. As postagens encontradas nos portfólio virtual no $P B W o r k s$ podem ser tomadas como fundamentos de um processo de construção de conhecimento que conduz à reflexão, porém, não significa que esse processo siga nesta direção. O registro das observações e relatos de atividades permite a organização das ideias, porém, é na constância das postagens e dos comentários dos coordenadores e colegas de programa que as transformações poderão ocorrer.

Podemos levantar a questão da importância do coordenador de área na supervisão da construção do portfólio, porém, o tempo necessário para a efetivação desse aprendizado dependerá de cada aluno, de seus hábitos de leitura e de escrita, ou seja, da sua capacidade de organização do pensamento e de construção textual.

Observamos no movimento de registrar, ver e transpor para o espaço virtual a vivência de uma situação escolar, por meio da arte e na abertura interdisciplinar, a possibilidade de integrar as diversas linguagens:

\footnotetext{
Aluna do curso de Teatro

Eu pensamento, nós conhecimento:

Fico pensando, talvez utopicamente, em uma escola aberta, onde não tenham divisões entre os conhecimentos; que não seja obrigatória, mas atrativa para que não precisasse ser obrigatória; onde pudéssemos compartilhar e nos fazermos presentes, pensantes e poetizantes do nosso mundo, sem ter que pensar a todo o tempo no futuro, mas sim entender o passado e buscar o tesão no presente, assim o futuro viria sem tantas tensões e responsabilidades massacrantes. O projeto em que estou, me proporciona essa alegria e dividir isso com meus colegas tem sido uma alegria constante, conversamos a cada semana na escola sobre essas ações que propomos, simples, mas que se revelaram grandes dispositivos de arte e que nos ajudam a entender esse espaço e a pensar sobre ele.
}

A reflexão proposta nesse registro é de uma escola sem grades, sem obrigatoriedades e com mais presença. O desejo de aprender e de usufruir do espaço está relacionado ao convívio e à interação com o outro. O espaço virtual exige a transposição para a escrita, que implica o uso da racionalidade e os limites que a língua impõe para essa efetivação. Na escrita poética é possível registrar as sensações que o corpo acolhe. O texto abaixo foi postado com a foto do portão da escola, chaveado. 
Aluna do curso de Teatro

Reflexões sobre grades, chaves e fechaduras...

Bom, elas demoram mas abrem.

Fico pensando se estivessem abertas o tempo todo.

As coisas seriam levadas, derrubadas, quebradas, reestruturadas?

Ou ninguém mais apareceria, ou iríamos poder entrar e sair a qualquer hora.

Ou outras pessoas apareceriam? Bom é assustadoramente e estranhamente tentador. Só para ver isso mudar. Ih, para de pensar besteira, a tia já abriu a porta e tu nem viu!

O registro abre o espaço de compartilhamento e eleva o pensamento ao reunir elementos observados de modo a construir raciocínio. As questões levantadas remetem aos possíveis efeitos de uma escola sem grades ou portas chaveadas. A referência à violência pode ser um elemento de resistência, e a abertura ao outro ("outras pessoas apareceriam") pode corresponder a um elemento de possibilidade e esperança.

O aprendizado no uso do PBWorks mereceu atenção e valorização por parte dos coordenadores ao longo do ano. Alguns manifestaram contrariedade e preocupação com a obrigatoriedade da tarefa, entendendo que isto deixa o processo de aprendizagem em segundo plano. O primeiro desafio citado foi de conciliar o uso de portfólios em papel com os portfólios virtuais. Para alguns professores, o portfólio virtual tem mais benefícios, pois oferece melhor condição de organização dos registros. Por outro lado, os inconvenientes são associados ao tipo de resultado obtido, quando a proposta exige a materialidade dos produtos gerados pelo processo.

Coordenadora de Área

- Diferença de acesso: o material físico está sempre à mão para ser feito ou apresentado, a conexão na rede, não.

- Diferença de expressão: há diferença em algumas das linguagens entre um e outro meio. Meio físico: desenho, colagem, escrita, coleção de objetos. Meio digital: vídeo (e edição), foto (e edição), digitalização de imagens, escritos. Cada um precisa de aprendizagens e de compreensões específicas. Nossos alunos ainda não são os nativos digitais, precisam ser introduzidos neste meio. Assim como estão também aprendendo a expressarem-se artisticamente por meios físicos, mas os portfólios físicos são mais autorais e criativos em sua visualidade.

- Diferença de habilidades fundamentais: no portfólio virtual é necessário que o aluno seja frequente leitor e escritor, uma vez que a linguagem escrita é a mais presente. Isso é bom para aquele aluno que já tem esta condição ou está disposto a desenvolver-se nisso, mas repele aquele que não tem a disposição necessária. A título de dar conta das produções, às vezes acontecem pequenos plágios ou pesquisas superficiais ou mesmo abandono do portfólio virtual.

- Diferença na "ansiedade": não encontro outra palavra neste momento, mas percebo que o portfólio digital gera ansiedade em relação às produções para os alunos e ansiedade nos professores quanto à organização do espaço, sistematização das tarefas e orientação de tudo. O portfólio físico tem uma inserção mais orgânica no tempo da vida, não gera a ansiedade da conexão em rede.

As questões levantadas pelos coordenadores remetem às diferentes formas de utilizar o portfólio virtual. De um lado, permite uma melhor organização para o aluno que necessita mais supervisão sobre seu trabalho e de outro lado, gera perdas, pois as ações pedagógicas exigem diferentes formas de expressão; diferentes linguagens que não podem ser transpostas de modo integral no meio virtual.

O debate sobre as diferenças entre o virtual e os termos que costumamos associar como seu oposto - o real, o material, o físico -, é analisado por Levy (1996). O virtual se opõe àquilo que já está constituído que é estático e possível - o atual. O modo de ser virtual contém uma mudança que pode ser atualizada de maneira mais ou menos inventiva. Assim, a virtualização é definida por Levy como "o movimento inverso da atualização" (1996, p. 17) e corresponde a uma mutação de identidade.

A virtualização dos portfólios com a substituição dos portfólios em papel problematizou o modelo de aprendizagem vigente. O eixo geográfico da centralidade espacial das unidades universitárias de cada cidade - ao qual licenciandos e 
coordenadores estão referenciados - se desloca para diferentes coordenadas de trabalho. Os subprojetos são reunidos de modo a formar um corpo, o site do projeto institucional, e estão conectados com diferentes coletividades que compartilham o espaço virtual. A principal modalidade da virtualidade é seu desprendimento do imediatismo do aqui e agora. A virtualização tira do objeto sua condição territorial e estática e o dispersa em várias projeções. A virtualidade é comparada por Levy (1996) como "abandonar a presença" no sentido de uma existência virtual.

Entendemos também, que o espaço virtual do PBWorks é um site ou situs, que é um lugar de referência, uma posição. Comparado com a noção de espaço euclidiano, é um endereço nômade. A virtualização coloca o sujeito em uma presença enquanto ausência e em uma unidade de tempo-espaço que situa uma posição, em vez de marcar um lugar geográfico e histórico.

Por outro lado, a crítica à virtualização nos é dada pelo filósofo e urbanista francês, Paul Virilio (1995), que parte da constatação de que a experiência proporcionada pelo ciberespaço é tátil. A perspectiva audiovisual nos faz ver a distância e ouvir a distância enquanto que aquela dada pela virtualização nos coloca em contato com a distância por meio do telecontato. A virtualidade gera rapidez e volume de informações, questão identificada pelos coordenadores de área e apontada como um fator que multiplica o trabalho dos envolvidos no processo.

O fenômeno da virtualidade, para Virilio (1995), está transformando as distâncias e superfícies em favor da noção de tempo de duração - um tempo extremamente curto ou extremamente longo -, impossível de ser registrado pela percepção. Importante registrar que essa impossibilidade gera perdas. A crítica sobre as consequências da virtualidade podem auxiliar na análise das resistências dos alunos e das dificuldades dos coordenadores para lidar com essas resistências. $\mathrm{O}$ espaço virtual promove informações e desinformações. As desinformações estão relacionadas com certa obstrução de sentidos e perda de controle sobre a razão de gêneros - imagens e opiniões; noções e relações; intuições. A resistência para a utilização do espaço virtual pode ser pensada como uma resistência diante de uma mudança estrutural.

\section{CONSIDERAÇÕES FINAIS}

A elaboração deste estudo permitiu uma aproximação com o processo de aprendizagem cooperativo presente na construção de portfólios virtuais no uso do PBWorks. As dificuldades citadas pelos alunos revelam a complexidade da aprendizagem no espaço virtual, pois envolve um contínuo movimento de apreensão, a descentração, a tomada de consciência, o reflexionamento, relações que configuram a presença na ausência, o reconhecimento da referência ao outro, posições éticas diante do material publicado no portfólio e a relação de cooperação e de solidariedade que mantêm o investimento no programa de iniciação à docência.

A identificação do caráter aleatório dos registros dos portfólios foi entendida, em parte, como efeito das características do meio virtual que impõe velocidade e quantidade de informações. Para enfrentar estes desafios entendemos ser necessário o investimento em leituras e debates das publicações de modo presencial e em interações virtuais com os coordenadores, incluindo a reflexão sobre posições éticas. A partir deste estudo, foi possível situar referências para a continuidade do acompanhamento do processo de construção dos portfólios no Pibid-Uergs.

\section{REFERÊNCIAS BIBLIOGRÁFICAS}

ALVARENGA, Geofravia M. e ARAÚJO, Zilfa R. Portfólio: conceitos básicos e indicações para utilização. Estudos em Avaliação Educacional, v. 17, n. 33, jan./abr. 2006.

BECKER, Fernando. Epistemologia do professor. O cotidiano da escola. $15^{\mathrm{a}}$. ed. Rio 
de Janeiro: Editora Vozes, 2009.

BONA, Aline Silva De e BASSO, Marcus Vinicius de Azevedo. Portfólios de Matemática: um instrumento de análise do processo de aprendizagem. RENOTE Revista de Novas Tecnologias na Educação. Vol. 7 n. 2, dezembro de 2009.

BONA, Aline Silva De e BASSO, Marcus Vinicius de Azevedo. Construção de Portfólios de Matemática usando o PBWorks. RENOTE - Revista de Novas Tecnologias na Educação. Vol. 8 n. 3, dezembro de 2010.

BRANQUINHO, Desidério M. O.; GOMES, Nelson G. Enciclopédia de Termos Lógico-Filosóficos, São Paulo: Martins Fontes, 2006, 803 pp.

CORBELINI, Silvana e CORTE REAL, Luciane M. C. Caleidoscópio: as multivisões facetadas da pesquisa cooperativa na Educação a Distância. In: Simpósio Internacional de Educação a Distância SIED 2012 e Encontro de Pesquisadores em Educação a Distância EnPED 2012, São Paulo, Anais do SIED, 2012.

CRUZ, José Marcos de Oliveira. Processo de ensino e aprendizagem na sociedade da informação. Educação \& Sociedade, vol. 29, n 105, Campinas, Set/Dez. 2008.

LÉVY, Pierre. O que é o virtual. São Paulo: Editora 34, 1996.

PIAGET, Jean. A tomada de consciência. São Paulo: Melhoramentos, 1977.

PIAGET, Jean. Abstração reflexionante: relações logico-matemáticas e ordem das relações espaciais. Porto Alegre: Artes Médicas, 1995.

REAL, Luciane M.C. CORBELLINI, Silvana e SANTOS,Gilberto Silva dos. O Moodle e o PBWorks: plataformas complementares na educação semipresencial. Segundo MoodleMootUY. 22 e 23 de novembro de 2012. Montenvideo, Uruguay. Disponível em http://www.moodlemoot.org.uy/moodlemoot_2012/sesiones/paper_33.pdf. Acesso em 17 de julho de 2015.

RODRIGUES, Maria Fernanda de C. C. C. Portfolio: Estratégia Formativa e de Reflexão na Formação Inicial em Educação de Infância. Dissertação de Mestrado, Universidade de Lisboa. 2009.

VIRILIO, Paul. Velocidad e información. ¡Alarma en el ciberespacio! Le monde diplomatique. Agosto de 1995. Disponível em

http://www.infoamerica.org/teoria_textos/virilio95.pdf. Acesso em 9 de novembro de 2014.

YIN, Robert. Estudo de caso: planejamento e método. $4^{\mathrm{a}}$. ed. Porto Alegre: Bookman, 2010. 